\title{
Relations Between Barley Root Traits and Osmotic Adjustment Under Terminal Drought Stress
}

\author{
Sanaz Afshari-Behbahanizadeh ${ }^{1}$, Gholam A. Akbari ${ }^{1}$, Maryam Shahbazi ${ }^{2} \&$ Iraj Alahdadi ${ }^{1}$ \\ ${ }^{1}$ Department of Agronomy and Plant Breeding, College of Aburaihan, University of Tehran, Tehran, Iran \\ ${ }^{2}$ Department of Molecular Physiology, Agriculture Biotechnology Research Institute of Iran (ABRII), Karaj, Iran \\ Correspondence: Gholam A. Akbari, Department of Agronomy and Plant Breeding, College of Aburaihan, \\ University of Tehran, Imam Reza Blvd, Pakdasht, Tehran, Iran. Tel: 98-21-3604-0615. E-mail:gakbari@ut.ac.ir
}

\author{
Received: April 22, 2014 Accepted: May 6, 2014 Online Published: June 15, 2014 \\ doi:10.5539/jas.v6n7p112 URL: http://dx.doi.org/10.5539/jas.v6n7p112
}

\begin{abstract}
The root responses to water deficit and osmotic adjustment are two main mechanisms that plants use to cope with drought stress. In order to evaluate relations between these mechanisms a greenhouse study was carried out in factorial based on CRD with three replications. In present work, three barley cultivars with different levels of drought tolerance have been subjected to terminal drought stress. Water stress was imposed by withholding water at the anthesis stage. The samplings were done when the available water content (AWC) in soil reached to $30 \%$ AWC (moderate stress) and 10\% AWC (severe stress). Biological yield (BY) and grain yield (GY) were calculated at the end of the growth period. The results indicated that by increasing water stress severity, water potential (WP), osmotic potential (OP) and root volume (RV) decreased. In contrast, osmotic adjustment (OA) was higher in drought tolerant cultivar, Yousof, in severe drought stress condition (10\% AWC). It seems that osmotic adjustment significantly caused to increase root to shoot ratio in this cultivar. Finally, the lowest grain yield reduction obtained from Yousof. The significant correlations were obtained between OA and root traits $(\mathrm{p}<0.05)$ in $10 \%$ AWC condition. The highest significant correlations were observed between OA and RWC ( $\mathrm{r}=+0.92), \mathrm{BY}(\mathrm{r}=+0.83)$, GY $(\mathrm{r}=+0.96)$ in $10 \%$ AWC condition $(\mathrm{p}<0.01)$. The results underline the efficient relations between different drought resistance mechanisms especially in drought tolerant cultivar.
\end{abstract}

Keywords: grain yield, osmotic potential, root volume, RWC, water potential

\section{Introduction}

Water shortage is the most abiotic stress factor limiting crop growth, development and production (Alqudah, Samarah, \& Mullen, 2011). Reduction in crop yield depends definitely on water limitation severity and the growth stage of plants that it happens. In according to cereal crops growing in areas with a Mediterranean climate which is the availability of water is scarce at the end of growth cycle, so the reproductive stage certainly will be affected by water limitation (González, Martin, \& Ayerbe, 2008).

Generally, barley (Hordeum vulgare L.) which is more drought tolerant than other Mediterranean cereals is cultivated in these areas, however, its productivity is limited by terminal water stress. Under condition of drought stress, looking for genotypes with effective physiological characteristics to cope with drought stress is required (Cantero-Martínez, Villar, Romagosa, \& Fereres, 1995).

Although identifying the physiological drought resistance mechanisms helps to improve yields under water deficient condition, the contribution of each mechanism should be evaluated firstly (Fukai \& Cooper, 1995). Drought resistant is made up four mechanisms; drought escape, drought tolerance, drought recovery, and drought avoidance. Among these mechanisms, root properties are related to drought avoidance (Gowda, Henry, Yamauchi, Shashidhar, \& Serraj, 2011).

Roots are the main organ of the plant and due to their impressive function in absorbing water and nutrients they play a pivotal role in plant growth and development (Gowda et al., 2011). Considering that roots directly contact with the soil, so they are the first organ sensing water shortage (Sicher, Timlin, \& Bailey, 2012). The water stress changes the length and volume of roots (Ober \& Sharp, 2007). Increasing root to shoot ratio is one of the most common response of plants to low soil water content (Sicher et al., 2012). 
On the other hand, one of the main mechanism affects the root elongation in the soil with low humidity is osmotic adjustment (Voetberg \& Sharp, 1991). Osmotic adjustment is considered as a drought tolerance mechanism (Hamidou, Zombre, \& Braconnier, 2007), and refers to reduction in water potential by net accumulation of organic and inorganic solutes, hence, it helps to remain the turgor pressure in high status at lower water potential, thus many physiological processes such as cell expansion, enzymes activities, stomata opening and gas exchanges, photosynthesis and growth, that depend on turgor, will be continued (Gonzalez et al., 2008; Zivcak, Repkova, Olsovska, \& Brestic, 2009; Daneshmand, Arvin, \& Kalantari, 2010). A positive and significant correlation was found between yield and osmotic adjustment capacity, RWC and water potential under drought stress conditions (Gonzalez et al., 2008). Whereas, genetic variations in osmotic adjustment existed among barley cultivars (González, Martin, \& Ayerbe, 1999), osmotic adjustment capacity and leaf water potential can be selected as characteristics to improve the drought tolerance in crops (Moinuddin, Fischer, Sayre, \& Reynolds, 2005; Nayyar, Kaur, Singh, Dhir, \& Bains, 2005). Morgan (1995) pointed out wheat cultivars with high osmotic adjustment ability clearly demonstrated higher yield than cultivars with low osmotic adjustment under drought stress condition. In spite of all advantages of osmotic adjustment, its potential as a drought tolerance mechanism has not been approved by all researchers. Some authors mentioned osmotic adjustment is a result of growth reduction caused by drought (Munns, 1988) and others showed osmotic adjustment solely acts under severe drought stress without any influential effect on yield (Serraj \& Sinclair, 2002).

Among the mechanisms which are known as the drought tolerance, osmotic adjustment has attracted much more attention in recent years (Serraj \& Sinclair, 2002). However, research studies about effects of drought stress on OA, yield and root traits together are still not clear. So this study was conducted to investigate: (1) the differences in osmotic adjustment mechanism in barley cultivars demonstrating different drought tolerance ability under terminal drought stress, (2) the relation between root traits and osmotic adjustment (3) the role of osmotic adjustment in water relations and grain yield under terminal drought stress in green house condition.

\section{Materials and Methods}

\subsection{Plant Material and Growth Conditions}

Three barley (Hordeum vulgare L.) cultivars; Yousof (drought tolerant), Fajr 30 (drought-sensitive) and Morocco (semi-drought tolerant) representing different agronomic traits under terminal drought stress in field condition were chosen for this study. For each cultivar, 400 seeds were allowed to germinate on filter paper moistened with distilled water for 24 hours in a growth chamber at $25 / 20^{\circ} \mathrm{C}$ (day/night) under $10 / 14$ hours (light/ dark). The germinating seeds were then transferred to pots ( 8 seeds per pot) containing a mixture of field soil, sand and manure (2:1:1) and maintained in the greenhouse condition at the Agricultural Biotechnology Research Institute of Iran (ABRII) in Karaj in 2011- 2012. For each cultivar 48 pots were considered and totally 144 pots used in this experiment. The experiment was conducted in factorial based on completely randomized design (CRD) with two treatments (well-watered and drought-stressed) and three replications.

Plants were grown under well-watered condition until anthesis. When the cultivars were at the anthesis stage, drought stress was started by withholding water but the control pots were irrigated daily (at $70 \%$ AWC) until maturity stage. When the soil moisture in drought stress pots reached to $30 \%$ AWC (moderate stress) and 10\% AWC (severe stress) (amounts of water content in the potting medium were determined gravimetrically), the flag leaves of the main stem of control and treated plants were sampled.

\subsection{Root Traits}

Roots were harvested in control and drought stressed pots, and washed in order to eliminate the potting mixture residue. In each water treatments and for each cultivar, measurements were performed on eight plants. Root volume was evaluated by immersion in a graduate test tube and measure of the displaced water volume. Root samples and above-ground tissue were immediately weighed to determine fresh weight of each part. The ratio of fresh root-to-shoot (FRW/FSW) was then calculated.

\section{$2.3 \mathrm{WP}, O P, O A$ and $R W C$}

The leaf was detached for measurement of its water potential (WP) using a pressure chamber (Soil Moisture Equipment, Santa Barbara, CA, USA). After taking water potential measurement, the leaf was immediately wrapped in polyethylene bag and plunged into liquid nitrogen and then transferred to $-20{ }^{\circ} \mathrm{C}$ freezer for later osmotic potential determination.

The leaves were thawing and then put in Eppendorf tubes with holes at the bottom. These tubes were then centrifuged twice, at $4000 \times \mathrm{g}$ for $4 \mathrm{~min}\left(4^{\circ} \mathrm{C}\right)$; in this way all sap was extracted from samples. The osmotic 
potential of the leaf sap was calculated, after measuring sap osmolarity with a vapor pressure osmometer (model 5520 XR, Wescor, Inc., Logan, UT, USA), by the van’t Hoff equation:

$$
\Psi=-M I R T
$$

Where $M$ is $\mathrm{mmol} / \mathrm{kg}, I=1, R=0.0083, T=\mathrm{t}(\mathrm{K})$.

To measure osmotic adjustment (OA), 4 excised flag leaves (in each replication) were rehydrated in distilled water for $24 \mathrm{~h}$, wrapped in polyethylene strips and then frozen at $-20^{\circ} \mathrm{C}$. After thawing at room temperature (about 15 $\mathrm{min})$, the cell sap was extracted and the osmotic potential (OP) of the extracted sap was determined using a vapor pressure osmometer (model 5520 XR, Wescor, Inc., Logan, UT, USA), as osmotic potential at full turgor (OP 100). Osmotic adjustment (OA) was evaluated as the difference between the (OP 100) of stressed and control plants (Blum, 1989):

$$
O A=\Psi S c 100-\Psi S \text { S } 100
$$

Flag leaves (4 flag leaves in each replication) were used to determine relative water content (RWC) according to the formula:

$$
R W C \%=(\text { Fresh weight-Dry weight }) /(\text { Turgid weight }- \text { Dry weight }) \times 100
$$

Turgid weight was obtained after leaves soaking overnight in distilled water at $4{ }^{\circ} \mathrm{C}$ in darkness and dry weight after $48 \mathrm{~h}$ at $72{ }^{\circ} \mathrm{C}$.

\subsection{Biomass and Grain Yield}

When the plants reached to physiological maturity stage, 10 spikes in each replication, cut, weighed and threshed to obtain the grain yield of each cultivar. The whole of plant was harvested in order to calculate the total biomass of the crop. The spike, grain and straw were oven-dried $\left(48 \mathrm{~h}\right.$ at $\left.72{ }^{\circ} \mathrm{C}\right)$ before weighing.

\subsection{Statistical Analysis}

All data were subjected to analysis of variance using the GLM procedure of SAS (Statistical Analysis System ver 9.1) and comparisons were made using Duncan's multiple range tests at $\mathrm{p}<0.05$.

\section{Results and Discussion}

\subsection{Root Traits}

Drought stress conditions, 30\% AWC (moderate stress) and 10\% AWC (severe stress), both of them caused reduction in RV, FRW and FSW as compared to control condition (70\% AWC) and cultivars significantly differed together in root traits (Table 1). Also, cultivars remarkably varied in fresh root to shoot ratio in different drought stress levels. At 30\% AWC the tolerant cultivar, Yousof, decreased FRS but semi-drought tolerant cultivar, Morocco, increased FRS and drought-sensitive cultivar, Fajr30, did not significantly change this trait, but in $10 \%$ AWC condition FRS in all cultivars considerably elevated and the higher ratio obtained from Yousof (Tables 3 \& 4).

\begin{tabular}{|c|c|c|c|c|c|c|c|c|c|c|c|c|c|}
\hline \multirow{3}{*}{ S.O.V } & \multirow{3}{*}{$\mathrm{df}$} & & & \multicolumn{10}{|c|}{ MS } \\
\hline & & \multicolumn{2}{|c|}{ Water Potential } & \multicolumn{2}{|c|}{ Osmotic Potential } & \multicolumn{2}{|c|}{ Relative Water content } & \multicolumn{2}{|c|}{ Fresh Root Weight } & \multicolumn{2}{|c|}{ Root Volume } & \multicolumn{2}{|c|}{ Fresh Shoot Weight } \\
\hline & & $(30 \%)$ & $(10 \%)$ & $(30 \%)$ & $(10 \%)$ & $(30 \%)$ & $(10 \%)$ & $(30 \%)$ & $(10 \%)$ & $(30 \%)$ & $(10 \%)$ & $(30 \%)$ & $(10 \%)$ \\
\hline water treatment & 1 & $5.644 * *$ & $26.305^{* *}$ & $7.875 * *$ & $24.647 * *$ & $6163.37 * *$ & $12200.18^{* *}$ & $0.559^{*}$ & $0.1341 * *$ & $0.7377^{*}$ & $0.4184 * *$ & $6.956^{* *}$ & $67.875 * *$ \\
\hline cultivar & 2 & $0.200 \mathrm{~ns}$ & $0.346^{* *}$ & $0.459 * *$ & $0.435^{* *}$ & $40.029 *$ & $166.75^{* *}$ & $1.764 * *$ & $0.1188 * *$ & $1.908 * *$ & $0.2049 * *$ & $15.138 * *$ & $5.138 \mathrm{~ns}$ \\
\hline water treatment $x$ cultivar & 2 & $0.479 * *$ & $0.856^{* *}$ & $0.342 * *$ & $0.544 * *$ & $121.1 * *$ & $40.260 \mathrm{~ns}$ & $0.569 * *$ & $0.0013 \mathrm{~ns}$ & $0.6064^{*}$ & $0.053 *$ & $0.898^{*}$ & $2.856 \mathrm{~ns}$ \\
\hline Error & 12 & 0.0527 & 0.0290 & 0.0359 & 0.0325 & 7.869 & 17.949 & 0.064 & 0.0043 & 0.0977 & 0.0103 & 0.1772 & 1.624 \\
\hline $\mathrm{CV}(\%)$ & & 13.8 & 7.2 & 8.7 & 6.7 & 3.8 & 7.4 & 31.09 & 12.2 & 33.36 & 15.2 & 8.59 & 25.43 \\
\hline
\end{tabular}

Table 1. Analysis of variance for some water relations, shoot and root traits of three barley cultivars under well-watered condition (70\% AWC) and terminal drought conditions (30\% and 10\% AWC) in greenhouse

$*$ and **: Significant at $5 \%$ and $1 \%$ probability levels, respectively and ns: Non-significant.

In drought stress conditions, root and shoot weight reduced (Tables $3 \& 4$ ), but the sensitivity of shoot growth to water deficit was more than root growth. Roots continue to grow in order to explore new soil volume for water 
hence, root to shoot ratio increased. Also, the ability of roots to grow in soils with low amount of water allows plants to survive when soil water is declining (Sharp et al., 2004).

Whereas, in 30\% AWC the tolerant Yousof cultivar decreased root to shoot ratio (Table 3), it is assumed that the applied stress condition was not severe enough for this tolerant cultivar and Yousof did not receive any stress and continued its usual growth but in 10\% AWC Yousof sensed the stress and may be by higher OA capacity in comparison with other cultivars, it increased ratio of root to shoot much more than the other cultivars.

\subsection{Osmotic Adjustment and Water Relations}

Drought stress conditions, 30\% AWC (moderate stress) and 10\% AWC (severe stress), both of them firmly reduced RWC, OP and WP in contrast to control condition $(70 \%$ AWC) and cultivars had a significant difference together in water relation traits (Table 1). As long as the drought stress intensified, the differences between the control and treated plants become greater in RWC, WP and OP (Tables 3 \& 4).

Also drought stress conditions enhanced OA capacity, but the reactions of these three cultivars to drought stress were considerably different. By increasing water stress severity, OA capacity elevated in the tolerant Yousof cultivar but semi-drought tolerant Morocco cultivar decreased OA capacity and drought-sensitive Fajr30 cultivar did not clearly change this trait (Figure 1a). The results showed some variations among cultivars in capacity of accumulation osmotic active compounds.
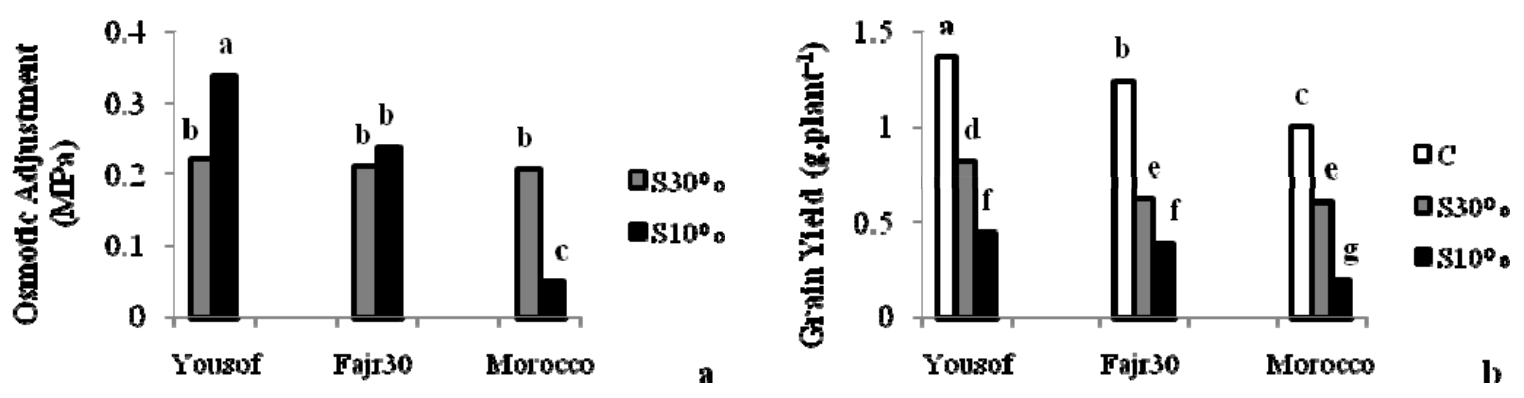

Figure 1. Comparisons the traits of barley cultivars in control (C), moderate drought stress (S 30\%) and severe drought stress (S 10\%) conditions in greenhouse

Osmotic adjustment is generally associated with active accumulation of solutes in cells as a response of reduction in water potential and permits cells to retain turgor pressure under water deficit. Osmotic adjustment obviously reduces the sensitivity of processes dependent on turgor, such as growth and stomatal activity, as water potential decreased (Daneshmand et al., 2010). The higher osmotic adjustment caused delayed stomatal closure and thus can be considered as advantageous for higher photosynthetic assimilation in water limited growing conditions in wheat (Zivcak et al., 2009).

Correlations between OA and other traits were not significant in 30\% AWC (data not shown), but in 10\% AWC, OA was positively correlated with root traits, RWC, BY and GY (Table 5). It seems that OA mechanism requires more time to accumulate solute content, so the rapid reductions in plant water status may not allow full expression of OA (Blum, 1996). The significant correlation provided some explanations for the close relations between the OA and other traits in all cultivar in severe stress. Present study is the evidence that OA can contribute to yield maintenance under severe drought condition in barley. In a study, a positive association was observed between yield and OA under severe water stress where yields tend to be low (Serraj \& Sinclair, 2002). In another research, OA was positively correlated with plant production under drought stress but not with plant production under irrigated conditions (Blum, Zhang, \& Nguyen, 1999). Finally, Gonzalez et al. (1999) reported that osmotic adjustment is an indispensable trait that leads to higher grain yields in barley grown under terminal water stress condition. Whereas, OA is directly linked to RWC, so we can say OA is merely an alteration in solute content per cell during drought stress, while changing in water content per cell also can occur during water stress but, this is not osmotic adjustment.

It seems that $\mathrm{OA}$ with the positive effects on root traits and by increasing root to shoot ratio, effectively enables plants to extract water from soil environment under drought stress and caused to maintain cell turgor pressure high, thus this mechanism contribute to sustain higher photosynthetic rate and expansion growth. Consequently, OA by 
affecting water relations caused delay senescence in plants and plants will have more opportunities to complete the growth cycle. Moinuddin et al. (2005) showed that osmotic adjustment can be an effective selection criterion for drought tolerance, and it has a serious role in reducing drought dependent yield loss especially when water deficit occurs during the reproductive growth stage.

These results clearly provided that different drought stress mechanisms closely related together in drought stress and it helps plants to survive in severe drought condition.

\subsection{Yield}

Drought stress had a significant effect on BY and GY and cultivars considerably varied in BY and GY $(\mathrm{p}<0.01)$ (Table 2). It seems that in drought stress conditions due to stomatal closure and early senescence, plants do not have enough time to transfer all photosynthetic assimilates to reproductive organ (Gonzalez et al., 2008; Daneshmand et al., 2010).

The interaction between drought stress and cultivar was significant on GY $(\mathrm{p}<0.05)$ (Table 2). By increasing drought stress severity, GY obviously decreased in all cultivars (Figure 1b). Yousof cultivar had the highest root to shoot ratio and OA capacity in $10 \%$ AWC as compared to the others, because of these two reasons, it had more opportunities to transfer assimilate to reproductive organ (spike) and grain, so it had the lowest grain yield reduction $(67 \%)$ in $10 \%$ AWC.

Yousof cultivar used two mechanisms to withstand drought stress, drought avoidance mechanism (increased root to shoot ratio) and drought tolerance mechanism (osmotic adjustment). Both of these mechanisms were profitable for maintaining grain yield in high level. So this cultivar had the highest grain yield. The results suggest that the cultivar with higher OA capacity may be has better root traits in drought stress conditions.

Table 2. Analysis of variance for OA and yield of three barley cultivars under well-watered condition ( $70 \% \mathrm{AWC})$ and terminal drought conditions ( $30 \%$ and $10 \%$ AWC) in greenhouse

\begin{tabular}{ccccc}
\hline S.O.V & \multirow{2}{*}{ df } & \multicolumn{3}{c}{ MS } \\
\cline { 3 - 5 } & & Osmotic Adjustment & Biological Yield & Grain Yield \\
\hline water treatment & 2 & $0.1336^{* *}$ & $4.721^{* *}$ & $1.6881^{* *}$ \\
cultivar & 2 & $0.0237^{* *}$ & $0.8119^{* *}$ & $0.1703^{* *}$ \\
water treatment $\times$ cultivar & 4 & $0.0206^{* *}$ & $0.1185 \mathrm{~ns}$ & $0.0130^{*}$ \\
Error & 18 & 0.0003 & 0.0498 & 0.0044 \\
\hline CV $(\%)$ & & 13.1 & 11.3 & 8.9
\end{tabular}

* and **: Significant at 5\% and 1\% probability levels, respectively and ns: Non-significant.

Table 3. Mean* comparison of some water relations, shoot and root traits of three barley cultivars under well-watered condition ( $70 \%$ AWC) and terminal drought condition $(30 \% \mathrm{AWC})$ in greenhouse

\begin{tabular}{|c|c|c|c|c|c|c|c|c|}
\hline Treatment & Cultivars & $\begin{array}{c}\text { Water } \\
\text { Potential } \\
(\mathrm{Mpa})\end{array}$ & $\begin{array}{c}\text { Osmotic } \\
\text { Potential } \\
\text { (Mpa) }\end{array}$ & $\begin{array}{c}\text { Relative Water } \\
\text { content }(\%)\end{array}$ & $\begin{array}{l}\text { Fresh Root } \\
\text { Weight } \\
\text { (g. plant }{ }^{-1} \text { ) }\end{array}$ & $\begin{array}{c}\text { Root } \\
\text { Volume } \\
(\mathrm{ml} . \\
\left.\text { plant }^{-1}\right)\end{array}$ & $\begin{array}{c}\text { Fresh } \\
\text { Shoot } \\
\text { Weight } \\
\left(\text { g. plant }{ }^{-1}\right)\end{array}$ & $\begin{array}{l}\text { Fresh } \\
\text { Root/ } \\
\text { Shoot }\end{array}$ \\
\hline \multirow{3}{*}{ Control } & Yousof & $-0.99 \mathrm{a}$ & $-1.38 \mathrm{a}$ & $86.62 \mathrm{~b}$ & $1.96 \mathrm{a}$ & $2.15 \mathrm{a}$ & $7.70 \mathrm{a}$ & $0.26 \mathrm{a}$ \\
\hline & Fajr 30 & $-1.05 \mathrm{a}$ & $-1.56 \mathrm{a}$ & $93.22 \mathrm{a}$ & $0.62 \mathrm{bc}$ & $0.74 \mathrm{~b}$ & $6.34 \mathrm{c}$ & $0.13 \mathrm{~b}$ \\
\hline & Morocco & $-1.24 \mathrm{a}$ & $-1.69 \mathrm{a}$ & $94.49 \mathrm{a}$ & $0.39 \mathrm{c}$ & $0.53 \mathrm{~b}$ & $4.23 \mathrm{c}$ & $0.09 \mathrm{~b}$ \\
\hline \multirow{3}{*}{$\begin{array}{c}\text { Stress }(30 \% \\
\text { AWC) }\end{array}$} & Yousof & $-2.25 \mathrm{c}$ & $-2.54 b$ & $57.21 \mathrm{c}$ & $0.90 \mathrm{~b}$ & $1.02 \mathrm{~b}$ & $5.66 \mathrm{~b}$ & $0.16 \mathrm{~b}$ \\
\hline & Fajr 30 & $-2.66 \mathrm{~d}$ & $-3.42 \mathrm{c}$ & $58.53 \mathrm{c}$ & $0.56 \mathrm{bc}$ & $0.62 \mathrm{~b}$ & $4.13 \mathrm{c}$ & $0.14 \mathrm{~b}$ \\
\hline & Morocco & $-1.74 b$ & $-2.56 b$ & $47.56 \mathrm{~d}$ & $0.46 \mathrm{bc}$ & $0.57 \mathrm{~b}$ & $3.04 \mathrm{~d}$ & $0.15 \mathrm{~b}$ \\
\hline
\end{tabular}

*Means, in each column, followed by similar letter are not significantly different at the $5 \%$ probability levelaccording to Duncan's Multiple Range Test. 
Table 4. Mean* comparison of some water relations, shoot and root traits of three barley cultivars under well-watered condition (70\% AWC) and terminal drought condition (10\% AWC) in greenhouse

\begin{tabular}{|c|c|c|c|c|c|c|c|c|}
\hline Treatment & Cultivars & $\begin{array}{l}\text { Water Potential } \\
\text { (Mpa) }\end{array}$ & $\begin{array}{c}\text { Osmotic } \\
\text { Potential (Mpa) }\end{array}$ & $\begin{array}{c}\text { Relative Water } \\
\text { content }(\%)\end{array}$ & $\begin{array}{l}\text { Fresh Root } \\
\text { Weight } \\
\text { (g. plant }{ }^{-1} \text { ) }\end{array}$ & $\begin{array}{l}\text { Root Volume } \\
\left(\text { ml. plant }{ }^{-1}\right)\end{array}$ & $\begin{array}{l}\text { Fresh Shoot } \\
\text { Weight } \\
\text { (g. plant }{ }^{-1} \text { ) }\end{array}$ & $\begin{array}{c}\text { Fresh Root/ } \\
\text { Shoot }\end{array}$ \\
\hline \multirow{3}{*}{ Control } & Yousof & $-0.98 b$ & $-1.35 \mathrm{a}$ & $86.43 \mathrm{a}$ & $0.80 \mathrm{a}$ & $1.14 \mathrm{a}$ & $8.79 \mathrm{a}$ & $0.094 \mathrm{c}$ \\
\hline & Fajr 30 & $-0.62 \mathrm{a}$ & $-1.49 \mathrm{a}$ & $82.77 \mathrm{a}$ & $0.53 \mathrm{~b}$ & $0.63 \mathrm{bc}$ & $6.29 \mathrm{a}$ & $0.085 \mathrm{c}$ \\
\hline & Morocco & $-1.81 \mathrm{c}$ & $-1.67 \mathrm{a}$ & $79.75 \mathrm{a}$ & $0.55 \mathrm{~b}$ & $0.69 \mathrm{~b}$ & $5.77 \mathrm{~b}$ & $0.098 \mathrm{bc}$ \\
\hline \multirow{3}{*}{$\begin{array}{c}\text { Stress }(10 \% \\
\text { AWC) }\end{array}$} & Yousof & $-3.52 \mathrm{~d}$ & $-3.61 b$ & $35.19 \mathrm{~b}$ & $0.61 \mathrm{~b}$ & $0.62 b c$ & $3.32 \mathrm{c}$ & $0.182 \mathrm{a}$ \\
\hline & Fajr 30 & $-3.72 \mathrm{~d}$ & $-4.46 \mathrm{c}$ & $35.42 \mathrm{~b}$ & $0.39 \mathrm{c}$ & $0.47 \mathrm{c}$ & $3.06 \mathrm{c}$ & $0.130 \mathrm{~b}$ \\
\hline & Morocco & $-3.43 \mathrm{~d}$ & $-3.46 \mathrm{~b}$ & $22.14 \mathrm{c}$ & $0.36 \mathrm{c}$ & $0.45 \mathrm{c}$ & $2.82 \mathrm{c}$ & $0.129 \mathrm{~b}$ \\
\hline
\end{tabular}

*Means, in each column, followed by similar letter are not significantly different at the $5 \%$ probability levelaccording to Duncan's Multiple Range Test.

Table 5. Pearson correlation coefficients between all traits of barley cultivars in severe drought stress condition $(10 \%$ AWC) in greenhouse

\begin{tabular}{lllllllllll}
\hline & WP & OP & OA & RWC & FRW & RV & FSW & FRS & BY & GY \\
\hline WP & 1 & & & & & & & & & \\
OP & $0.70^{*}$ & 1 & & & & & & & & \\
OA & $-0.23 \mathrm{~ns}$ & $-0.27 \mathrm{~ns}$ & 1 & & & & & & & \\
RWC & $-0.30 \mathrm{~ns}$ & $-0.48 \mathrm{~ns}$ & $0.92^{* *}$ & 1 & & & & & & \\
FRW & $0.07 \mathrm{~ns}$ & $0.33 \mathrm{~ns}$ & $0.75^{*}$ & $0.52 \mathrm{~ns}$ & 1 & & & & & \\
RV & $-0.04 \mathrm{~ns}$ & $0.32 \mathrm{~ns}$ & $0.63^{*}$ & $0.41 \mathrm{~ns}$ & $0.93^{* *}$ & 1 & & & & \\
FSW & $0.06 \mathrm{~ns}$ & $0.06 \mathrm{~ns}$ & $0.65^{*}$ & $0.52 \mathrm{~ns}$ & $0.59 \mathrm{~ns}$ & $0.56 \mathrm{~ns}$ & 1 & & & \\
FRS & $0.05 \mathrm{~ns}$ & $0.33 \mathrm{~ns}$ & $0.63^{*}$ & $0.42 \mathrm{~ns}$ & $0.94^{* *}$ & $0.87^{* *}$ & $0.27 \mathrm{~ns}$ & 1 & & \\
BY & $-0.25 \mathrm{~ns}$ & $-0.59 \mathrm{~ns}$ & $0.83^{* *}$ & $0.89^{* *}$ & $0.39 \mathrm{~ns}$ & $0.17 \mathrm{~ns}$ & $0.41 \mathrm{~ns}$ & $0.29 \mathrm{~ns}$ & 1 & \\
GY & $-0.26 \mathrm{~ns}$ & $-0.42 \mathrm{~ns}$ & $0.96^{* *}$ & $0.91^{* *}$ & $0.66^{*}$ & $0.51 \mathrm{~ns}$ & $0.58 \mathrm{~ns}$ & $0.56 \mathrm{~ns}$ & $0.89^{* *}$ & 1 \\
\hline
\end{tabular}

$*$ and ${ }^{* *}$ Significant at $5 \%$ and $1 \%$ probability levels, respectively and ns: Non-significant.

WP: water potential, OP: osmotic potential, OA: osmotic adjustment, RWC: relative water content, FRW: fresh root weight, RV: root volume, FSW: fresh shoot weight, FRS: Fresh Root/ Shoot, BY: Biological Yield, GY: Grain Yield.

\section{Conclusion}

In accordance with the results of this study, terminal drought stress at anthesis stage could affect water relations, root traits and also reduced grain yield in barley cultivars. Plants use different mechanisms to cope with drought stress such as increasing root to shoot ratio and osmotic adjustment. The positive correlation between osmotic adjustment, root traits and grain yield in severe drought stress (10\% AWC) conclusively revealed a relationship between the drought avoidance mechanism (increasing root to shoot ratio) and drought tolerance mechanism (osmotic adjustment). Although the drought tolerant cultivar effectively used both mechanisms to maintain its performance under water stress condition, while the semi-drought tolerant and drought sensitive cultivars could not behave in the similar way.

\section{Acknowledgments}

We thank the staff of the greenhouse at the Agricultural Biotechnology Research Institute of Iran (ABRII) in Karaj for technical assistance. 


\section{References}

Alqudah, A. M., Samarah, N. H., \& Mullen, R. E. (2011). Drought stress effect on crop pollination, seed set, yield and quality. In E. Lichtfouse (Ed.). Alternative farming systems, biotechnology, drought stress and ecological fertilization, Sustainable Agriculture, Reviews 6 (pp. 193-215). Springer. http://dx.doi.org/10.1007/978-94007-0186-1_6

Blum, A. (1989). Osmotic adjustment and growth of barley genotypes under drought stress. Crop Science, 29(1), 230-233. http://dx.doi.org/10.2135/cropsci1989.0011183X002900010052x

Blum, A. (1996). Crop responses to drought and the interpretation of adaptation. Plant Growth Regulation, 20, 135-148. http://dx.doi.org/10.1007/BF00024010

Blum, A., Zhang, J., \& Nguyen, H, T. (1999). Consistent differences among wheat cultivars in osmotic adjustment and their relationship to plant production. Field Crops Research, 64, $287-291$. http://dx.doi.org/10.1016/S0378-4290(99)00064-7

Cantero-Martinez, C., Villar, J. M., Romagosa, I., \& Fereres, E. (1995). Growth and yield responses of two contrasting barley cultivars in a Mediterranean environment. European Journal of Agronomy, 4, 317-326.

Daneshmand, F., Arvin, M. J., \& Kalantari, K. M. (2010). Physiological responses to NaCl stress in three wild species of potato in vitro. Acta Physiologiae Plantarum, 32, 91-101. http://dx.doi.org/10.1007/S11738 -009-0384-2

Fukai, S., \& Cooper, M. (1995). Development of drought resistant cultivars using physiomorphological traits in rice. Field Crops Research, 40, 67-86. http://dx.doi.org/10.1016/0378-4290(94)00096-U

Gonzalez, A., Martin, I., \& Ayerbe, L. (1999). Barley yield in water- stress conditions.: The influence of precocity, osmotic adjustment and stomatal conductance. Field Crops Research, 62, 23-34. http://dx.doi.org/10.1016/S0378-4290(99)00002-7

Gonzalez, A., Martin, I., \& Ayerbe, L. (2008). Yield and osmotic adjustment capacity of Barley under terminal water- stress conditions. Journal of Agronomy and Crop Science, 194, 81-91. http://dx.doi.org/10.1111/j.1439-037X.2007.00289.x

Gowda, V. R. P., Henry. A., Yamauchi, A., Shashidhar, H. E., \& Serraj R. (2011). Root biology and genetic improvement for drought avoidance in rice. Field Crops Research, 122, 1-13. http://dx.doi.org/10.1016/j.fcr.2011.03.001

Hamidou, F., Zombre, G., \& Braconnier, S. (2007). Physiological and biochemical responses of cowpea genotypes to water stress under glasshouse and field conditions. Journal of Agronomy and Crop Science, 193, $229-237$. http://dx.doi.org/10.1111/j.1439-037X.2007.00253.X

Moinuddin, A., Fischer, R. A., Sayre, K. D., \& Reynolds, M. P. (2005). Osmotic adjustment in wheat in relation to grain yield under water deficit environments. Agronomy Journal, 97, 1062-1071. http://dx.doi.org/10.2134/ agronj2004.0152

Morgan, J. M. (1995). Growth and yield of wheat lines with differing osmoregulative capacity at high soil water deficit in seasons of varying evaporative demand. Field Crops Research, 40, 143-152. http://dx.doi.org/10.1016/0378-4290(94)00100-Q

Munns, R. (1988). Why measure osmotic adjustment? Functional Plant Biology, 15, 717-726. http://dx.doi.org/10.1071/PP9880717

Nayyar, H., Kaur, S., Singh, K. J., Dhir, K. K., \& Bains T. (2005). Water stress-induced injury to reproductive phase in chickpea: Evaluation of stress sensitivity in wild and cultivated species in relation to abscisic acid and polyamines. Journal of Agronomy and Crop Science, 191, 450-457. http://dx.doi.org/10.1111/j.1439-037X.2005.00184.x

Ober, E. S., \& Sharp, R. E. (2007). Regulation of root growth responses to water deficit. In M. A. Jenks (Ed.), Advances in molecular breeding toward drought and salt tolerant crops (pp. 33-53). Springer, New York.

Serraj, R., \& Sinclair, T. R. (2002). Osmolyte accumulation: can it really help increase crop yield under drought conditions? Plant, Cell \& Environment, 25, 333-341. http://dx.doi.org/10.1046/j.1365-3040.2002.00754.x

Sharp, R. E., Poroyko, V., Hejlek, L. G., Spollen, W. G., Springer, G. K., Bohnert, H. J., \& Nguyen, H. T. (2004). Root growth maintenance during water deficits: physiology to functional genomics. Journal of Experimental Botany, 55(407), 2343-2351. http://dx.doi.org/10.1104/jxb/erh276 
Sicher, R. C., Timlin, D., \& Bailey, B. (2012). Responses of growth and primary metabolism of water-stressed barley roots to rehydration. Journal of plant physiology, 169, 686-695. http://dx.doi.org/10.1016/j.jplph. 2012.01 .002

Voetberg, G. S., \& Sharp, R. E. (1991). Growth of the maize primary root at low water potentials. III. Role of increased proline deposition in osmotic adjustment. Plant Physiology, 96, 1125-1130. http://dx.doi.org/10.1104/pp.96.4.1125

Zivcak, M., Repkova, J., Olsovska, K., \& Brestic, M. (2009). Osmotic adjustment in winter wheat varieties and its importance as a mechanism of drought tolerance. Cereal Research Communications, 37, 569-72.

\section{Copyrights}

Copyright for this article is retained by the author(s), with first publication rights granted to the journal.

This is an open-access article distributed under the terms and conditions of the Creative Commons Attribution license (http://creativecommons.org/licenses/by/3.0/). 